Quine's misgivings over synonymy may well be justified, but they do not affect the intelligibility of $\mathrm{P}$ and $\mathrm{Q}$. My epistemic reading of Church's phrase 'conveys different meanings', as incorporated in principle Q, clearly avoids appeal to the notion of sameness of meaning; likewise the extensional reading given in $\mathrm{P}^{*}$ to the notion of sameness of information.

Lest these replies make me seem uncharitable, let me conclude by granting that if Church were to need $\mathrm{R}, \mathrm{S}$ or $\mathrm{T}$ to argue successfully against Carnap's analysis of belief, then the above objections would be very serious stumbling blocks indeed. What I have tried to show in this paper is that there exists a version of his argument which can succeed with much less. ${ }^{2}$

(C) ARnold Cusmariu 1982

${ }^{2}$ I have been helped by comments from Herbert Heidelberger, Michael Levin, Philip Quinn and from Professor Church.

\title{
THE CONCEPT OF EXPERIENCE AND STRAWSON'S TRANSCENDENTAL DEDUCTION
}

\section{By KIM DAVIES}

IN The Bounds of Sense (Methuen 1966) Professor Strawson I claims that the conclusion of Kant's Transcendental Deduction, namely that the contents of experience must be brought under concepts of an objective world, represents a 'very great and novel' gain in epistemology (p. 29). I wish to argue that closer consideration of the concept of experience with which Strawson, following Kant, begins, pre-empts the whole project.

Strawson sets out the following thesis assumed as a premise in (his reconstruction of) the Transcendental Deduction:

that there must be such unity among the members of some temporally extended series of experiences as is required for the possibility of selfconsciousness, or self-ascription of experiences, on the part of a subject of such experiences (the thesis of the necessary unity of consciousness) (p. 24).

This thesis is linked with the dual character of experience (viz. that particular contents of experience should be recognized as having some general character) and, as so linked, is taken as a 'standard-setting definition of what is to count as "experience", (p. 25). Why should we begin with this definition? Strawson notes that other forms of sentience, short of this standard, may exist, but goes on to argue not only that no other philosopher 'even the most 
economical of empiricists' has tried to work with a more limited conception (p. 25), but that only this concept of experience 'can be of interest to us' (p. 28-9). It is not clear to me that writers such as Hume, Russell and Ayer do in fact build the possibility of selfconsciousness into their concept of experience, but I wish to discuss the question of the interest which binds together the community indicated by Strawson's first-person plural.

The interest which a concept of experience has for 'us' is presumably to be understood in the light of the purposes 'we' share. Of course, we do in fact self-ascribe experiences, but dogs and babies do not, and it might be thought that this less sophisticated form of sentience was of more interest. To see why it is not, we should ask why the concept of experience is important for philosophy. It seems to me clear that its fundamental significance lies in its opening a gap, between how things are experienced as being and how they are, which is the ground of the possibility of any critical philosophy. In the light of the possible disparity between how things are and how they are experienced as being, the question of the justification of claims to knowledge emerges. Without the recognition of this possible disparity, this epistemological gap, the interrogration of knowledge-claims which is central to all philosophy (other than the 'angels on pins' type) would not be possible. It underlies the Cartesian Doubt and those traditions in Western Philosophy which followed in its wake. Now it would seem that for someone to possess the concept of experience required here, and to recognize the epistemological gap, the self-ascription of experience is required - it looked as though $\mathrm{X}$, but in fact $\mathrm{Y}$ - or at least that self-reflexiveness of experience which for Strawson constitutes the core of empirical self-consciousness (p. 111). Thus can we understand the philosophical interest of a concept of experience into which the possibility of self-ascription is built. And if experience is to provide a kind of alternative to successful cognition of an objective world, on the basis of which we can call for the justification of knowledge-claims, then it must have the dual character Strawson talks of, at least insofar as it must comprise some kind of awareness or consciousness of some kind of item, which recognizes that item as falling under a general concept. Thus can we understand the philosophical interest of the second component of Strawson's concept of experience, so that it may seem that we must agree with him that his definition as a whole is 'surely acceptable'.

Let us first look closer at the 'object' side of this concept. Strawson's word is 'accusative', indicating that it is internal to the experience, and not necessarily (at this stage) conceived of as independent of experience. If it were so conceived, then the claim that concepts of the objective must be used in experience would be built into the concept of experience from the start, so that an argument to that effect would hardly be required. But this is precisely what must be the case if the concept of experience is to be adequate to 
the philosophical purposes it is to serve. For unless experience is of items conceived of as independent of experience itself, there would be no possibility of opening up a gap between how things are and how they are experienced as being, and so no possibility of critical philosophical thought. If experience involved nothing more than an awareness of an item which made no claim to be independent of experience, for example the red patches and tickling sensations of the sense-datum theorists (p. 99), then there could be no disparity between how things are experienced as being and how they are, since there would be nothing more to how things are than how they are experienced as being. That experience is of items conceived of as existing independently of experience itself, that those items are brought under 'concepts of the objective', must already be built in to that concept of experience which is to be of fundamental interest to us. Without this as the primary concept of experience, Kant could never have faced a scandal, nor Strawson his sceptic. Strawson's reconstruction of the Transcendental Deduction can succeed only in reaching the point which it first started from.

Although this account retains the value of some of Kant's Analytic, particularly the Analogies which lay out the necessary structure of the conception of an objective world in terms of substance and causality, and although the kind of considerations prompted by Kant's arguments have a value which transcends this argument itself, the fact that it takes a major thread of the Deduction to be, at bottom, idle, might call for more discussion. How is it possible that Kant, and then Strawson, could have failed to recognize this? The answer lies in a forgetfulness of the provenance of their concept of experience inscribed in their work. We can see how, on the basis of a concept of experience as primarily of items brought under concepts of the objective, we could recognize that some experiences do not have this character, and then wish to generalize our concept to that of an awareness of an item, where nothing is presupposed about the nature of that item. It is not then difficult to focus, in the spirit of scientific generality, on this concept at the cost of a gradual amnesia concerning the circumstances in which it emerged, and the features needed for the primary concept to serve its philosophical purpose. This is effectively what occurred between the time of Descartes and Hume; Kant (with Strawson following) takes up Hume's problems and with them the concept of experience which they presuppose. Now there is certainly some intrinsic interest in showing that if one starts with this concept, then the contents of experience must be brought, at least in part, under concepts of the objective. It nevertheless remains the case that this requirement must be built into any concept of experience which, as the ground of the possibility of the demand for justification, can be of fundamental significance to critical philosophy, and so explain the philosophical interest which Strawson speaks vaguely of. That the Transcendental Deduction 
can be held to have secured very great and novel gains is thus a mark of the thoroughness with which critical philosophy forgets its beginnings, and of the need for the kind of philosophical selfreflection attempted here.

University of Durham

(C) KIM DAvIES 1982

\title{
MACKIE'S DEFENCE OF INDUCTION
}

\author{
By P. J. R. MILLICAN
}

I

HUME's attack on induction is very familiar: that the past be a rule for the future cannot be established deductively, whilst any inductive argument to that conclusion would itself depend on it, and so be circular. But Hume takes for granted that there are no other kinds of reasoning available besides deduction and induction, and therefore assumes that the possibilities for justification of the latter are exhausted, since neither of them is adequate to the task. If his rigid dichotomy is accepted, Hume's argument indeed seems compelling. Recently, however, it has been challenged by those who see a third possibility, and I would like to consider, as one representative of this approach, J. L. Mackie's attempt to provide a probabilistic justification of induction. ${ }^{1}$

Mackie sets himself the task of justifying a prediction of general uniformity for a limited period, a prediction which can then itself be used to support other, particular inductions. He considers first the simple pair of rival hypotheses, that the world's ways of working are completely uniform throughout, and that they are completely random. 'If we had just these alternatives to choose between, it would be reasonable to prefer the former in the light of our observations, unless it was antecedently almost infinitely less probable than the second.' And to assume that it was so vastly improbable would, of course, be question-begging.

Unfortunately, the matter is complicated by the profusion of other possible hypotheses, even if we accept it to be overwhelmingly probable that the world has in fact been completely uniform during the period of our past observations. For it could be that this uniformity has a limited temporal (or spatial) range, beyond which it terminates or gradually fades out. These hypotheses of extensive

'J. L. Mackie, 'A Defence of Induction', in G. F. Macdonald (ed.), Perception and Identity (London and Basingstoke: Macmillan, 1979). 